\title{
A high-selenium lentil dietary intervention in Bangladesh to counteract arsenic toxicity: study protocol for a randomized controlled trial
}

Regina M. Krohn ${ }^{1}$, Rubhana Raqib², Evana Akhtar ${ }^{2}$, Albert Vandenberg ${ }^{3^{*}}$ and Judit E. G. Smits ${ }^{1}$

\begin{abstract}
Background: Millions of people worldwide are exposed to dangerous levels of arsenic (above the WHO water standard of $10 \mathrm{ppb}$ ) in drinking water and food. Lack of nutritious foods exacerbates the adverse health effects of arsenic poisoning. The micronutrient selenium is a known antagonist to arsenic, promoting the excretion of arsenic from the body. Studies are in progress examining the potential of using selenium supplement pills to counteract arsenic toxicity. We are planning a clinical trial to test whether high-selenium lentils, as a whole food solution, can improve the health of arsenic-exposed Bangladeshi villagers.
\end{abstract}

Methods/design: A total of 400 participants (about 80 families) will be divided into two groups via computergenerated block randomization. Eligibility criteria are age $(\geq 14)$ years) and arsenic concentration in the household tube well $(\geq 100 \mathrm{ppb})$.

In this double-blind study, one group will eat high-selenium lentils grown in western Canada; the other will consume low-selenium lentils grown in Idaho, USA. Each participant will consume $65 \mathrm{~g}$ of lentils each day for 6 months. At the onset, midterm, and end of the trial, blood, urine and stool, plus hair (day 1 and at 6 months only) samples will be collected and a health examination conducted including assessment of acute lung inflammation, body mass and height, and blood pressure. The major outcome will be arsenic excretion in urine and feces, as well as arsenic deposition in hair and morbidity outcomes as assessed by a biweekly questionnaire. Secondary outcomes include antioxidant status, lipid profile, lung inflammation status, and blood pressure.

Discussion: Selenium pills as a treatment for arsenic exposure are costly and inconvenient, whereas a whole food approach to lower the toxic burden of arsenic may be a practical remedy for Bangladeshi people while efforts to provide safe drinking water are continuing. If high-selenium lentils prove to be effective in counteracting arsenic toxicity, agronomic partnerships between Canada and Bangladesh will work to improve the selenium content of the Bangladeshi-grown lentil crops. Results will be presented to the community to promote informed food choices, which may include increasing selenium in their diet.

Trial registration: ClinicalTrials.gov NCT02429921

Keywords: Chronic arsenic poisoning, High-selenium lentils, Arsenic body burden, Dietary intervention

\footnotetext{
*Correspondence: bert.vandenberg@usask.ca

${ }^{3}$ Department of Plant Sciences, University of Saskatchewan, 51 Campus Drive,

Saskatoon, SK S7N 5A8, Canada

Full list of author information is available at the end of the article
} 


\section{Background}

In the 1970s, the United Nations International Children's Emergency Fund (UNICEF) and the Bangladeshi government, followed by private initiatives, installed millions of tube wells in rural Bangladesh in an effort to reduce infant and child mortality caused by water-borne diseases such as cholera and other diarrheas [1,2]. Tragically, many of these deeper wells contained arsenic, which leaches from the bedrock into the groundwater. It was not until the 1990s, when people developed previously unknown skin lesions, that more extensive well water testing revealed the scale and severity of the arsenic problem. By then millions of people had been exposed to arsenic for more than 20 years [3].

In 2002, the World Health Organization (WHO) described the case of Bangladesh as "the world's largest mass poisoning of a population in history..." [4]. At that time it was estimated that between 35 and 77 million people were exposed to dangerously high concentrations of arsenic - above the WHO guideline of $10 \mathrm{ppb}$ and frequently above the national standard in Bangladesh of $50 \mathrm{ppb}$. It is noteworthy that food such as rice is irrigated with arsenic-contaminated shallow tube well water, potentially adding to the toxic burden [5].

The annual cost to treat arsenic-related health problems in Bangladesh is currently estimated at up to $\$ 77.5$ million [6].

A number of studies have found an association between the detrimental effects of arsenic exposure and malnutrition [7-9], which is also a prominent health concern in the Bangladeshi population, especially in children [10]. Chen et al. found that the risk of developing arsenicrelated skin lesions was greatly enhanced with low blood selenium. Selenium and arsenic work antagonistically in the body by competing in many biological functions [11]. In the blood, selenium interacts with arsenic to form a complex which is excreted in the bile [12], thereby lowering the arsenic body burden. Thus, higher selenium intake may be crucial to combat arsenic toxicity. Selenium levels in food are dependent on selenium bioavailability in the soil. Limited data are available on the selenium content of soils in Bangladesh. Initially it was found that agricultural soil in Bangladesh $(n=19)$ contains good selenium levels [13]. However, the authors determined that only $12 \%$ of selenium was soluble, reducing the immediately available selenium to $0.12 \mu \mathrm{g} / \mathrm{g}$. A "nutritional selenium deficiency" in soil is $<0.5 \mu \mathrm{g} / \mathrm{g}$ soil [14]; therefore, Bangladeshi soil falls into the selenium deficient category. The US dietary recommended daily allowance (US-RDA) for selenium for an adult is $55 \mu \mathrm{g} /$ day [15], and Spallholz et al. (2008) estimated that Bangladeshis consume about $26 \mu \mathrm{g} /$ day [13], approximately half of the RDA.

Supplementation of selenium in pill form is currently recommended to treat arsenicosis. However, pills are not often well received by people and are expensive for lowincome families. Lentils are a very common food in Bangladesh, with the major lentil imports coming from Canada, a world leader in lentil exports. In crop year 2011/2012, 47,620 tonnes (metric tons) of lentils were exported to Bangladesh, and in 2012/2013 this increased to 90,800 tonnes (metric tons) [16]. Saskatchewan (SK) grown lentils are naturally rich in selenium, mostly in the form of L-selenomethionine, which is highly bioavailable [17]. Saskatchewan lentils have mean selenium levels between $425-672 \mu \mathrm{g} / \mathrm{kg}$, with the levels in some regions as high as $1884 \mu \mathrm{g} / \mathrm{kg}$ [18]. Experimental studies in animal models demonstrated that diets made of highselenium lentils counteract arsenic toxicity and reduce arsenic-related atherosclerosis [19, 20]. Incorporated into the daily meals of arsenic-exposed Bangladeshi families, high-selenium lentils may help mitigate the symptoms of long-term arsenic poisoning in a cost-effective, culturally acceptable, and nutritionally beneficial way.

\section{Trial objectives}

The hypothesis of the trial is that consumption of highselenium lentils from Saskatchewan, Canada, will reduce the body burden of arsenic and decrease arsenic toxicity in a chronically arsenic-exposed Bangladeshi population compared to those consuming low-selenium lentils.

The primary objective was to perform a double-blind, randomized controlled trial to determine whether incorporation of high-selenium lentils into the daily diet, providing at least the RDA of Se (55 ug), can decrease the body burden of arsenic, evident by higher excretion in urine and/or feces and decreased deposition in hair, compared to the treatment group on low-selenium lentil consumption. Secondary objectives were to determine if consumption of high-selenium lentils:

1. improves antioxidant status

2. reduces oxidative DNA damage

3. changes acute phase proteins as well as serum lipid levels in arsenic-exposed individuals

4. decreases arsenic-related lung inflammation measured using exhaled nitric oxide as an indirect indicator

5. improves the body mass index (BMI) and blood pressure of arsenic-exposed individuals

Herein, we describe the design and methods protocol for our 3-year study now underway.

\section{Methods/design}

This trial protocol has been approved by the University of Calgary's Conjoint Health Research Ethics Board (Ethics ID: REB13-1211-Mod3), the University of Saskatchewan's Biomedical Research Ethics Board (Bio-No. 14-212), plus 
the Research Review Committee, the Ethics Review Committee, and the Data and Safety Monitoring Board (DSMB) of the International Centre for Diarrhoeal Disease Research, Bangladesh (Icddr,b) (Protocol No. PR-14013). Any changes to the trial protocol are communicated to the relevant parties and ethics boards. The trial will be reported according to SPIRIT (Standard Protocol Items: Recommendations for Intervention Trials) 2013 [21] (see Additional file 1). A summary of the trial according to the WHO Trial Registration Minimal Data Set is provided in Table 1 [22].

\section{Study settings}

The study is a parallel, double-blind, randomized controlled trial. Participants for this trial will be recruited from the communities of Shahrasti and Chandpur, Bangladesh, where arsenic levels in tube well water frequently exceed the national standard of $50 \mathrm{ppb}$. Families in these rural areas typically have their own tube well in the yard from which they collect their drinking and cooking water. Entire families will be recruited.

\section{Inclusion criteria}

The inclusion criteria are as follows:

1. Families who are exposed to arsenic levels $\geq 100 \mathrm{ppb}$ in their drinking water will be included in the trial.

2. All family members aged 14 and above will be enrolled if they agree.

\section{Exclusion criteria}

The exclusion criteria are as follows:

1. Children under the age of 14 will not be included in the trial, although they will also eat the highselenium or control lentils like the rest of the family.

2. Families whose tube well water has arsenic levels $<100 \mathrm{ppb}$ will be excluded from the trial.

3. If any family member(s) appears unhealthy, anemic for example, the family will not be recruited.

\section{Justification for eligibility criteria}

The national standard for arsenic in drinking water is $50 \mathrm{ppb}$. To increase the possibility of detecting clinical differences between the two treatments, we chose families with wells having arsenic levels above the national standard and $\geq 100 \mathrm{ppb}$. Moreover, after testing all the tube wells of potential participants, we identified only 10 out of 118 wells that had arsenic levels between 50 and $100 \mathrm{ppb}$. This resulted in a small sample size for this subgroup, which may not produce interpretable results and could weaken the statistical power of the whole trial.
Table 1 WHO Trial Registration Minimal Data Set according to Moja et al. [22]

\begin{tabular}{ll}
\hline Data & Information \\
\hline Trial identification number & ClinicalTrials.gov NCT02429921 \\
Trial registration date & April 21, 2015 \\
Secondary IDs & REB13-1211 (CHREB, University of Calgary), \\
& PR-14013 (ERC, icddr,b)
\end{tabular}

Funding sources

Global Institute for Food Security (GIFS); Grand Challenges Canada - Stars in Global Health Round 5

Primary sponsor

JEGS, Faculty of Vet. Med, University of Calgary, Canada

Secondary sponsor

RR, icddr,b, Dhaka, Bangladesh

Responsible contact person

RR, icddr,b; rubhana@icddrb.org

Research contact person

JEGS, Faculty of Vet. Med., University of Calgary; jegsmits@ucalgary.ca

Brief title of the study

High-selenium Lentils Versus Arsenic Toxicity

Official title of the study

Mitigating arsenic toxicity in Bangladeshi people by supplementing their diets with high selenium lentils

Country of recruitment Bangladesh

Health problem studied

Chronic arsenic poisoning

Intervention

Key inclusion and exclusion criteria

Study type

Trial start date

Target sample size

Recruitment status

Primary outcome

High-selenium lentils, control: lowselenium lentils

Inclusion criteria: families with $>100 \mathrm{ppb}$ As in their well water; ages eligible for study: 14-75

Exclusion criteria: As content of well water $\leq 100 \mathrm{ppb}$; ill health detected during initial recruitment health check

Double blind, parallel, block-randomized, controlled intervention trial

September 28, 2015

200 per treatment group (400 in total)

Active

Arsenic body burden: We will determine if high-Se lentil consumption will decrease the body burden of As by measurement of As excretion in urine and feces and deposition in hair

Key secondary outcomes We will determine if high-Se lentils:

$$
\begin{aligned}
& \text { 1. Increase concentrations of protective } \\
& \text { antioxidants and reduce oxidative stress } \\
& \text { and acute phase response in blood } \\
& \text { 2. Modulate serum lipid profile and blood } \\
& \text { pressure } \\
& \text { 3. Reduce As-related lung inflammation }
\end{aligned}
$$

We planned to include children of ages 10-17 in the trial, as they are a vulnerable group and actively developing, especially those from ages 10 to 14 . The observation of changes in nutritional status in these children due to lentil consumption would be especially valuable in our opinion. However, the Ethics Review Committee at icddr,b 
stipulated that children under the age of 14 be excluded from the study. Nevertheless, all family members of study participants, including young children, will eat the highselenium or control lentils.

\section{Consent}

Informed consent will be obtained from all adults, which includes their children in the trial, and assent forms are collected from every recruited child between 14-18 years of age (see Additional files 2 and 3). All forms have been translated into Bangla, and the recruiters will explain the trial procedures in detail and answer any questions the participants may have.

\section{Interventions and compliance}

Families will be randomly assigned to one of two interventions:

1. High-selenium lentils

2. Low-selenium lentils

For a period of 6 months, each participant will be required to eat $65 \mathrm{~g}$ lentils each day. The group that receives the high-selenium lentils will therefore consume at least the US-RDA of $55 \mu \mathrm{g}$ selenium per day. Apart from lentil supply, the other food consumed daily will not be controlled, so study participants who are in the low-selenium lentil group will also receive selenium from other food sources as usual, but this is expected to be similar between groups. The female family head will measure $65 \mathrm{~g}$ lentils per family member each day (a measuring cup will be provided) and will prepare foods, such as dal (lentil soup) and lentil patties, that are generally eaten by the family members over the day. The field staff will visit families twice a week in the first month of the intervention to promote and record compliance in lentil consumption. To ensure and confirm compliance, the lentil supply will be distributed weekly, and study participants will complete a lentil consumption questionnaire on a weekly basis for the duration of the trial.

We performed a 1-week pilot trial with four families to determine likelihood of compliance. The four families received the adequate amount of lentils (purchased from the local market) for 1 week, and consumption was monitored. All families did eat the required amount of lentils. The female family head used different recipes to incorporate the lentils into the daily meals.

\section{Safety considerations}

We do not expect any adverse effects from lentil consumption regardless of the treatment groups since both types of lentils are already traded and consumed worldwide. The group that will consume the high-selenium lentils will receive the US-RDA of $55 \mu \mathrm{g}$ of selenium per day, plus the average of $23 \mu \mathrm{g}$ selenium in the regular Bangladeshi diet acquired through other components, primarily fish and meat [13]. The current tolerable upper intake levels of selenium for humans are $280 \mu \mathrm{g} /$ day (9-13 years) and $400 \mu \mathrm{g} /$ day (ages 14+) according to the Dietary Supplement Fact Sheet from the National Institutes of Health, USA [23]. Supplementation of selenium at $200 \mu \mathrm{g} /$ day in studies of up to 13 years duration - in addition to other dietary selenium intake - lowers the risk of cancers, enhances cell-mediated immune function, decreases progression of chronic infectious diseases, inflammation and autoimmune diseases, and presents no evidence of toxicity [24-27]. Hence, even if study participants consumed double the amount of lentils a day, their selenium intake would be well below toxic levels and would likely be beneficial to their health.

An independent DSMB at icddr,b has been formed which will conduct periodic meetings and report the occurrence of adverse or seriously adverse events, if any. In this highly unlikely event, unblinding would be permissible.

\section{Sample size}

We determined the sample size for this trial with an online power and sample size calculator (www.powerand samplesize.com), based on a one-sided effect for arsenic concentration in hair.

Based on a previous intervention trial [28], in which arsenic-exposed participants received selenium-enriched yeast $(100-200 \mu \mathrm{g} / \mathrm{day}$, an amount two to four times higher than our dietary treatments), we calculated the sample size from their data generated after a 9-month intervention. Using the mean arsenic levels in hair of the control and selenium-treatment groups, $\operatorname{Mean}_{\mathrm{A}}=2.01 \mu \mathrm{g} / \mathrm{g}$ $( \pm 1.4)$ and $\mathrm{Mean}_{\mathrm{B}}=1.23( \pm 0.73)$, respectively, and a type I error of 0.05 and a power of 0.80 , we calculated a minimum participant number of 26 per treatment group. This sample size underestimates our needed sample size due to substantial differences from our planned trial. Considering the up to fourfold lower selenium treatment in our trial, we felt it was prudent to quadruple the number $(=100)$ and then double it to accommodate our larger age range, shorter duration, and loss to follow-up, arriving at the final participant number of 200 .

\section{Randomization and blinding}

This trial will be double-blinded. High- and low-selenium lentils have been packed in color-coded bags (green and white), and neither the study participants nor the study investigators know of the lentil type.

Related families commonly live in the same Bari (group of homes on one plot of land) in rural Bangladesh, with families, defined as members taking meals from the same cooking pot, living in individual homes or households 
(HHs) in the Bari. All family members in an $\mathrm{HH}$ will receive the same lentil type. However, within each Bari individual $\mathrm{HHs}$ may receive different lentil types. Once families are recruited, they will be assigned to treatment group A or B (deficient or high-selenium lentil groups) using a computer-generated block randomization method, and one group will be randomly assigned to receive selenium-rich lentils. The sample size is 200 individuals per group. Typically a family consists of four to eight members. Thus, if there are six members per $\mathrm{HH}$, there will be approximately $34 \mathrm{HH}$ per group. For the block randomization we may consider blocks of variable length, e.g., four or six HHs per block; thus, in each block there will be four or six HHs. Equal numbers of $\mathrm{HHs}$ are distributed in the two groups, and either group may receive the selenium-rich lentils. All $\mathrm{HHs}$ will receive their supply of lentils weekly. Sequential numbers will be allocated to the participants, e.g., 010101, 010102 (Bari 01, HH 01, family member 01, 02, 03...), etc.

\section{Lentil production and analysis}

Small, red, fast-cooking lentils, the preferred kind in Bangladesh, were grown for the trial. Lentils grown in the northwestern USA are low in selenium [18]. In the summer of 2014 a location near Genesee, Idaho was chosen for growing the low-selenium lentils, while the highselenium lentils were grown at Lucky Lake, Saskatchewan, Canada. All lentils were processed (dehulled, polished, and bagged in colored 25-kg bags) in a lentil dehulling and exporting facility in Vanscoy, Saskatchewan.

Samples of the lentils were analyzed for essential minerals, phytic acid, and macronutrients (Table 2). Idaho lentils contain $0.029 \mathrm{ppm}$ selenium; the Saskatchewan lentils contain $0.854 \mathrm{ppm}$ selenium. The lentils were tested for radiation biosafety certification by the Saskatchewan Research Council, Saskatoon, which declared the two lentil lots fit for human consumption.

\section{Lentil shipment and storage}

Five metric tons of each lentil type were shipped from Vanscoy, Saskatchewan, to the port in Chittagong, Bangladesh, where they were tested again for radiation and phytotoxins, a protective measure to prevent importation of contaminated grain. Once released the lentils were trucked to icddr,b Dhaka, where each bag was uniquely numbered and stored at room temperature.

\section{Recruitment}

At present, we are recruiting study participants. Two senior field site staff and three village health workers are visiting eligible $\mathrm{HHs}$ to obtain consent/assent from adults and children, respectively. The staff will collect sociodemographic data at that time via questionnaire.
Table 2 Macronutrient and micronutrient content of the two lentil types

\begin{tabular}{llll}
\hline Macronutrients & Measure & Sask. lentils & Idaho lentils \\
\hline Protein & \% by weight & 26.22 & 27.73 \\
Starch & \% by weight & 38.00 & 37.00 \\
TDF & \% by weight & 8.48 & 6.66 \\
Fat & \% by weight & 0.78 & 0.77 \\
Ash & \% by weight & 2.77 & 3.16 \\
Phytochemicals & & & \\
Phytic acid & $\mathrm{g} / \mathrm{kg}$ & 0.61 & 0.72 \\
Minerals & & & \\
Calcium & $\mathrm{mg} / \mathrm{kg}$ & 327.88 & 377.51 \\
Potassium & $\mathrm{g} / \mathrm{kg}$ & 10.45 & 10.94 \\
Sodium & $\mathrm{mg} / \mathrm{kg}$ & 71.74 & 75.00 \\
Magnesium & $\mathrm{mg} / \mathrm{kg}$ & 786.30 & 943.00 \\
Copper & $\mathrm{mg} / \mathrm{kg}$ & 9.34 & 11.44 \\
Iron & $\mathrm{mg} / \mathrm{kg}$ & 75.75 & 65.3 \\
Zinc & $\mathrm{mg} / \mathrm{kg}$ & 42.15 & 51.9 \\
Manganese & $\mathrm{mg} / \mathrm{kg}$ & 16.95 & 14.61 \\
Selenium & $\mathrm{mg} / \mathrm{kg}$ & 0.854 & 0.029 \\
Arsenic & $\mathrm{mg} / \mathrm{kg}$ & $<0.001$ & $<0.001$ \\
\hline Abbreia & &
\end{tabular}

Abbreviation: TDF total digestible fiber

\section{Study procedures}

After obtaining consent, families (four to six per week) visit the field office for baseline sample collection and physical examination and for completing the initial morbidity questionnaire. After this first visit, weekly lentil distribution and consumption starts.

The flow chart shows the complete 6-month study procedures (Fig. 1).

At baseline (day 1), midterm (3 months), and at the end of the study (6 months), samples will be collected as described in the following paragraph.

Urine $(15-20 \mathrm{ml})$ will be collected in trace-element free tubes, aliquoted, and stored at $-80{ }^{\circ} \mathrm{C}$. Stool samples (5-10 g) will be collected in trace-element free tubes from a subset (about 40) of participants and stored at $-20{ }^{\circ} \mathrm{C}$. Blood $(10 \mathrm{ml} / \mathrm{visit})$ will be collected in traceelement free tubes (S-Monovette ${ }^{\oplus}$, Sarstedt). Blood samples, in cool boxes, will be sent to the Dhaka Lab on the same day for separation into plasma and cells, and aliquots of plasma will be stored at $-80{ }^{\circ} \mathrm{C}$. Buffy coat cells will be stored in an RNAlater freezer at $-80{ }^{\circ} \mathrm{C}$. Whole blood $(100 \mu \mathrm{l})$ will be stored at $-80{ }^{\circ} \mathrm{C}$. Hair will be collected from the back of the head, close to the nape of the neck (approximately $0.2 \mathrm{~g}$ ) for analysis of arsenic.

Samples may be stored for up to 5 years for future analyses.

The following physical examinations will be performed at baseline, midterm, and end of study: 


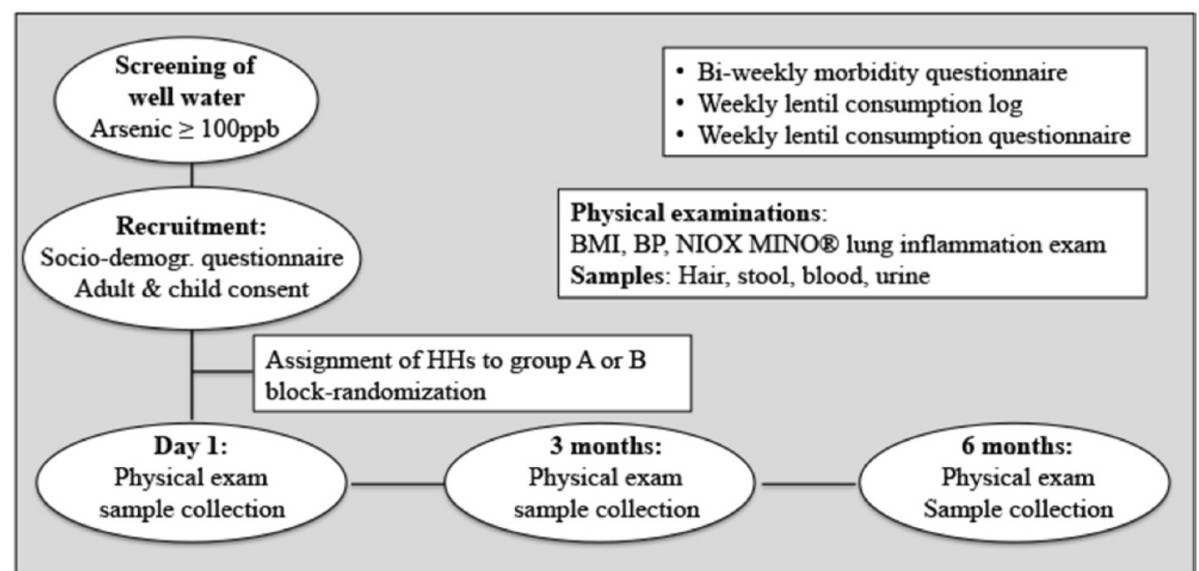

Fig. 1 Flow chart of the dietary intervention trial; BMl, body mass index; BP, blood pressure; HHs, households

1. Height and weight are measured to calculate body mass index (BMI).

2. Blood pressure (BP) is tested because of the association between arsenic and hypertension [29].

3. Lung inflammation (NIOX $\mathrm{MINO}^{\circ}$ ) - study participants exhale into a machine which detects exhaled nitric oxide, a marker for eosinophilic airway inflammation [30]. Previous reports showed an association of arsenic exposure with respiratory effects and inflammatory response of airway cells $[31,32]$.

\section{Laboratory methods}

Selenium will be measured in blood by graphite furnace atomic absorption spectrometry (GFAAS). Arsenic in hair, stool, and urine samples will be measured by hydride generation atomic absorption spectrometry (HGAAS) after acid digestion of samples. For determining oxidative stress and antioxidant status, we will measure 8-hydroxy-2'deoxyguanosine (8-OHdG), a major product of reactive oxygen species (ROS)-induced oxidative stress, in urine/ plasma using commercial ELISA kits. Selenium-dependent glutathione peroxidase uses reduced glutathione (GSH) to scavenge ROS, resulting in the production of oxidized GSSG [33]. The antioxidant status (GSH/GSSG) will be assessed with ELISA analysis as described previously $[20,34]$. Lipid profiles will be determined in serum by measuring triglyceride, total cholesterol, high-density lipoprotein (HDL), and low-density lipoprotein (LDL) cholesterol using commercial kits from Roche diagnostics on their automated clinical chemistry analyzer Cobas e601 (Roche Diagnostics, Mannheim, Germany). Acute phase response will be determined by analyzing Hs-CRP and $\alpha_{1}$-acid glycoprotein (AGP) in serum using the automated analyzer.

\section{Data analysis}

Data are stored in a password-protected database at icddr,b, through a platform that allows sharing of data between project investigators (PIs) at icddr,b and the University of Calgary. Statistical analyses will be done using the statistical software SPSS for Windows PASW version 20. Normality and homogeneity of variances will be determined. Data not normally distributed will be transformed as necessary. Initially Spearman's correlation analyses will evaluate univariate association between arsenic exposure (urinary and hair arsenic) and outcome variables (oxidative stress, antioxidant status, lung inflammatory status, and genetic variables). Covariates (e.g., demographic and socioeconomic variables, morbidity, daily diet, and BMI of participants) will be evaluated for significant association with exposure and outcomes. Missing data are excluded from that specific analysis. Significantly correlated variables will be further analyzed in multiple linear regression models controlling for potential confounding variables stratified by sex. Potential confounders will be identified based on correlations $(p<0.15)$ with the exposure (toxic metal) and outcomes and will be included in the final models when they change the effect estimate for metal exposure on the outcome by $5 \%$ or more.

\section{Discussion}

This trial is the first to use a high-selenium food source, i.e., lentils, in an attempt to combat the adverse health effects of chronic arsenic poisoning. Since lentils are an excellent source of non-animal protein and micronutrients such as $\mathrm{Zn}$ and Fe [35], we expect to see an improved BMI after 6 months of supplementation and possibly improved overall health status in all participants of the trial, regardless of the selenium content of the 
lentils. As a result, some of the proposed biomarkers may not be significantly different between the control and the high-selenium groups. However, since selenium can form a complex with arsenic, selenium supplementation, in principle, can reduce arsenic toxicity. We expect to see a significant decrease in the body burden of arsenic, the primary outcome of this study, in the highselenium group. Mild beneficial effects of selenium have been indicated in a number of supplementation trials with selenium alone or in combination with other micronutrients [36-38]; more trials are needed for conclusive evidence.

If we can prove that health benefits occur due to consumption of high-selenium lentils in arsenic-exposed communities, the first step will be to inform the Bangladeshi public - through a follow-up meeting with the participants and local media - and to promote consumption of higher-selenium food sources. Here again, the female family head will be the one responsible for purchasing and preparing nutritious food for the family.

Furthermore, we will disseminate the study results to the Food Planning and Monitoring Unit (FPMU) of the Ministry of Food, the Government of Bangladesh, and provide evidence-based advice for policy formulation on lentil import and agricultural aspects. The results may guide Bangladeshi importers to specifically target importation of high-selenium lentils.

The long-term goal toward food security will entail working on agronomic techniques to increase the production of high-selenium lentils in Bangladesh.

\section{Trial status}

Participants are currently being recruited.

\section{Additional files}

Additional file 1: SPIRIT_checklist. (DOC $121 \mathrm{~kb})$

Additional file 2: Adult consent form. (PDF $987 \mathrm{~kb}$ )

Additional file 3: Child assent form. (PDF $88 \mathrm{~kb}$ )

\section{Abbreviations}

8-OHdG: 8-hydroxy-2'-deoxyguanosine; BMI: body mass index; BP: blood pressure; CRP: C-reactive protein; GFAAS: graphite furnace atomic absorption spectrometry; GSH: reduced glutathione; GSSG: oxidized glutathione; HDL: high-density lipoprotein; HGAAS: hydride generation atomic absorption spectrometry; HH: household; LDL: low-density lipoprotein; ppb: parts per billion; RDA: recommended daily allowance; ROS: reactive oxygen species.

\section{Competing interests}

The authors declare that they have no competing interests.

\section{Authors' contributions}

All authors contributed significantly to the study design. RMK, EA, RR, and JES are study investigators. AV organized the lentil production, processing, and shipping. All authors contributed to writing and approved of the final version of the manuscript.

\section{Acknowledgements}

We would like to thank Grace Kwong for statistical advice and Mishu Dey and Mohammad Mia for collection and testing of tube well water. We thank Gene Arganosa and Barry Goetz for the lentil nutrient analysis.

\section{Funding}

Sponsors of this trial are Grand Challenges Canada (S5 0387-01) and the Global Institute for Food Security, University of Saskatchewan.

\section{Author details}

'Department of Ecosystem \& Public Health, Faculty of Veterinary Medicine, University of Calgary, 3280 Hospital Drive, Calgary, AB T2N 4Z6, Canada. ${ }^{2}$ International Centre for Diarrhoeal Disease Research, Bangladesh (icddr,b), 68, Shaheed Tajuddin Ahmed Sarani, Mohakhali, Dhaka 1212, Bangladesh. ${ }^{3}$ Department of Plant Sciences, University of Saskatchewan, 51 Campus Drive, Saskatoon, SK S7N 5A8, Canada.

Received: 19 January 2016 Accepted: 14 April 2016

Published online: 27 April 2016

\section{References}

1. Ahsan H, Perrin M, Rahman A, Parvez F, Stute M, Zheng Y, et al. Associations between drinking water and urinary arsenic levels and skin lesions in Bangladesh. J Occup Environ Med. 2000;42:1195-201.

2. Caldwell BK, Caldwell JC, Mitra SN, Smith W. Searching for an optimum solution to the Bangladesh arsenic crisis. Soc Sci Med. 2003;56:2089-96.

3. Chowdhury UK, Biswas BK, Chowdhury TR, Samanta G, Mandal BK, Basu GC, et al. Groundwater arsenic contamination in Bangladesh and West Bengal, India. Environ Health Perspect. 2000;108:393-7.

4. WHO. Arsenic - Mass poisoning on an unprecedented scale [press release] Geneva: WHO; 2002. http://www.who.int/features/archives/feature206/en/.

5. Das HK, Mitra AK, Sengupta PK, Hossain A, Islam F, Rabbani GH. Arsenic concentrations in rice, vegetables, and fish in Bangladesh: a preliminary study. Environ Int. 2004;30:383-7.

6. WHO. Arsenic: Fact sheet no. 372, December 2012. Geneva: WHO; 2012. http://www.who.int/mediacentre/factsheets/fs372/en/.

7. Vahter ME. Interactions between arsenic-induced toxicity and nutrition in early life. J Nutr. 2007;137:2798-804.

8. Minamoto K, Mascie-Taylor CG, Moji K, Karim E, Rahman M. Arseniccontaminated water and extent of acute childhood malnutrition (wasting) in rural Bangladesh. Environ Sci. 2005;12:283-92.

9. Chen CJ, Wu MM, Lee SS, Wang JD, Cheng SH, Wu HY. Atherogenicity and carcinogenicity of high-arsenic artesian well water. Multiple risk factors and related malignant neoplasms of blackfoot disease. Arteriosclerosis. 1988;8:452-60.

10. Das SK, Chisti MJ, Malek MA, Das J, Salam MA, Ahmed T, et al. Changing childhood malnutrition in Bangladesh: trends over the last two decades in urban-rural differentials (1993-2012). Public Health Nutr. 2015;18:1718-27.

11. Zeng $H$, Uthus EO, Combs Jr GF. Mechanistic aspects of the interaction between selenium and arsenic. J Inorg Biochem. 2005;99:1269-74.

12. Gailer J, George GN, Pickering IJ, Prince RC, Younis HS, Winzerling JJ. Biliary excretion of [(GS)(2)AsSe](-) after intravenous injection of rabbits with arsenite and selenate. Chem Res Toxicol. 2002;15:1466-71.

13. Spallholz JE, Mallory Boylan L, David Robertson J, Smith L, Rahman MM, Hook J, et al. Selenium and arsenic content of agricultural soils from Bangladesh and Nepal. Toxicol Environ Chem. 2008;90:203-10.

14. Oldfield JE. Selenium world atlas. Updated ed. Grimbergen, Belgium: Selenium-Tellurium Development Association; 2002. p. 1-59. http://www. 369.com.cn/En/Se\%20Atlas\%202002.pdf.

15. Monsen ER. Dietary reference intakes for the antioxidant nutrients: vitamin C, vitamin E, selenium, and carotenoids. J Am Diet Assoc. 2000;100:637-40.

16. Agriculture SMo. 2013 Specialty Crop Report. 2013. http://publications.gov. sk.ca/documents/20/83782-57e075f3-2dfe-420b-9c65-a027fb1ee61c.pdf.

17. Thavarajah D, Vandenberg A, George GN, Pickering IJ. Chemical form of selenium in naturally selenium-rich lentils (Lens culinaris L.) from Saskatchewan. J Agric Food Chem. 2007;55:7337-41.

18. Thavarajah D, Thavarajah $P$, Sarker A, Materne M, Vandemark G, Shrestha R, et al. A global survey of effects of genotype and environment on selenium concentration in lentils (Lens culinaris L.): Implications for nutritional fortification strategies. Food Chem. 2011;125:72-6. 
19. Sah S, Vandenberg A, Smits J. Treating chronic arsenic toxicity with high selenium lentil diets. Toxicol Appl Pharmacol. 2013;272:256-62.

20. Krohn RM, Lemaire M, Negro Silva LF, Lemarie C, Bolt A, Mann KK, et al. High-selenium lentil diet protects against arsenic-induced atherosclerosis in a mouse model. J Nutr Biochem. 2016;27:9-15.

21. Chan AW, Tetzlaff JM, Altman DG, Laupacis A, Gotzsche PC, Krleza-Jeric K, et al. SPIRIT 2013 statement: defining standard protocol items for clinical trials. Ann Intern Med. 2013;158:200-7.

22. Moja LP, Moschetti I, Nurbhai M, Compagnoni A, Liberati A, Grimshaw JM, et al. Compliance of clinical trial registries with the World Health Organization minimum data set: a survey. Trials. 2009:10:56.

23. NIH. Selenium: dietary supplement fact sheet. Bethesda, MD: NIH; 2013.

24. Finley JW. Selenium accumulation in plant foods. Nutr Rev. 2005;63:196-202.

25. Kiremidjian-Schumacher L, Roy M, Wishe HI, Cohen MW, Stotzky G. Supplementation with selenium and human immune cell functions. II. Effect on cytotoxic lymphocytes and natural killer cells. Biol Trace Elem Res. 1994:41:115-27.

26. Clark LC, Dalkin B, Krongrad A, Combs Jr GF, Turnbull BW, Slate EH, et al. Decreased incidence of prostate cancer with selenium supplementation: results of a double-blind cancer prevention trial. Br J Urol. 1998;81:730-4.

27. Thomson CD. Assessment of requirements for selenium and adequacy of selenium status: a review. Eur J Clin Nutr. 2004:58:391-402.

28. Yang LS, Wang WY, Hou SF, Peterson PJ, Williams WP. Effects of selenium supplementation on arsenism: an intervention trial in Inner Mongolia. Environ Geochem HIth. 2002;24:359-74.

29. Chen C-J, Wang S-L, Chiou J-M, Tseng C-H, Chiou H-Y, Hsueh Y-M, et al. Arsenic and diabetes and hypertension in human populations: a review. Toxicol Appl Pharmacol. 2007;222:298-304.

30. Kharitonov SA, Barnes PJ. Exhaled biomarkers. Chest. 2006;130:1541-6.

31. Milton AH, Rahman M. Respiratory effects and arsenic contaminated well water in Bangladesh. Int J Environ Health Res. 2002;12:175-9.

32. Dutta K, Prasad P, Sinha D. Chronic low level arsenic exposure evokes inflammatory responses and DNA damage. Int J Hyg Environ Health. 2015;218:564-74.

33. Allan CB, Lacourciere GM, Stadtman TC. Responsiveness of selenoproteins to dietary selenium. Annu Rev Nutr. 1999;19:1-16.

34. Reglero MM, Taggart MA, Monsalve-González L, Mateo R. Heavy metal exposure in large game from a lead mining area: effects on oxidative stress and fatty acid composition in liver. Environ Pollut. 2009;157:1388-95.

35. Wang N, Daun JK. Effects of variety and crude protein content on nutrients and anti-nutrients in lentils (Lens culinaris). Food Chem. 2006;95:493-502.

36. Verret WJ, Chen Y, Ahmed A, Islam T, Parvez F, Kibriya MG, et al. A randomized, double-blind placebo-controlled trial evaluating the effects of vitamin $\mathrm{E}$ and selenium on arsenic-induced skin lesions in Bangladesh. J Occup Environ Med. 2005;47:1026-35.

37. Kibriya MG, Jasmine F, Argos M, Verret WJ, Rakibuz-Zaman M, Ahmed A, et al. Changes in gene expression profiles in response to selenium supplementation among individuals with arsenic-induced pre-malignant skin lesions. Toxicol Lett. 2007;169:162-76.

38. Mahata J, Argos M, Verret W, Kibriya MG, Santella RM, Ahsan H. Effect of selenium and vitamin $\mathrm{E}$ supplementation on plasma protein carbonyl levels in patients with arsenic-related skin lesions. Nutr Cancer. 2008;60:55-60.

\section{Submit your next manuscript to BioMed Central and we will help you at every step:}

- We accept pre-submission inquiries

- Our selector tool helps you to find the most relevant journal

- We provide round the clock customer support

- Convenient online submission

- Thorough peer review

- Inclusion in PubMed and all major indexing services

- Maximum visibility for your research

Submit your manuscript at www.biomedcentral.com/submit

) Biomed Central 